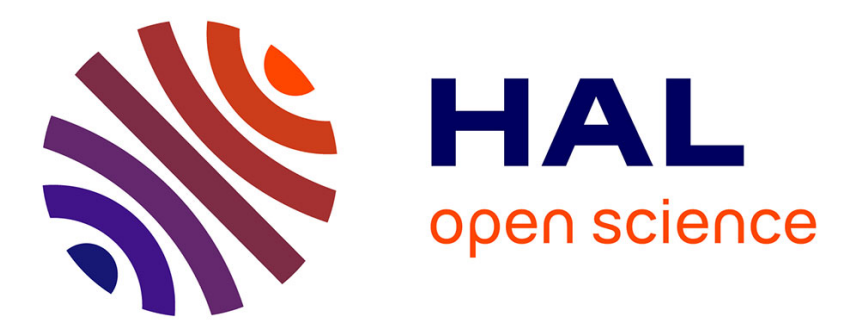

\title{
Comment on "Near-IR luminescence characteristics of monovalent bismuth in Bi-doped pure silica optical fibre: First-principle study"
}

Igor M. Razdobreev, Oleksii Laguta

\section{- To cite this version:}

Igor M. Razdobreev, Oleksii Laguta. Comment on "Near-IR luminescence characteristics of monovalent bismuth in Bi-doped pure silica optical fibre: First-principle study". Journal of Luminescence, 2018. hal-01945427

\author{
HAL Id: hal-01945427 \\ https://hal.science/hal-01945427
}

Submitted on 13 Oct 2021

HAL is a multi-disciplinary open access archive for the deposit and dissemination of scientific research documents, whether they are published or not. The documents may come from teaching and research institutions in France or abroad, or from public or private research centers.
L'archive ouverte pluridisciplinaire HAL, est destinée au dépôt et à la diffusion de documents scientifiques de niveau recherche, publiés ou non, émanant des établissements d'enseignement et de recherche français ou étrangers, des laboratoires publics ou privés. 


\title{
Comment on "Near-IR luminescence characteristics of monovalent bismuth in Bi-doped pure silica optical fibre: First-principle study"
}

\author{
Igor M. Razdobreev ${ }^{\mathrm{a}, *}$, Oleksii V. Laguta ${ }^{\mathrm{b}}$ \\ ${ }^{\text {a } U n i v . ~ L i l l e, ~ C E R L A, ~ C N R S, ~ U M R ~} 8523$ - PhLAM - Physique des Lasers, Atomes et Molecules, F59000 Lille, France \\ ${ }^{\mathrm{b}}$ Institut für Physikalische Chemie, Universität Stuttgart, Pfaffenwardring 55, D-70569 Stuttgart, Germany
}

\section{A R T I C L E I N F O}

\section{Keywords:}

Laser materials

Fibre materials

Near-IR luminescence

Monovalent bismuth

Transition energy

The title paper [1] reports the results of first-principle study of univalent Bismuth in the pure silica fibre or, in other words, in the silica glass without other co-dopant. The Authors claim that the obtained results are consistent with most of experimental data and that the calculations provide the useful guidance to fabricate bismuth-doped optical materials. In what follows, we show that the energy level diagrams discussed in the above paper are absolutely inconsistent with the experimental data.

\section{Luminescence in the spectral region 1.4-1.7 $\mu \mathrm{m}$}

First of all, in all the proposed energy level diagrams the transitions in the spectral range 1.4-1.7 $\mu \mathrm{m}$ take place between two excited states. The energy gaps between the lowermost of the excited states involved in this transition and the ground state are $3.9 \mathrm{eV}(0.32 \mu \mathrm{m}), 3.4 \mathrm{eV}$ $(0.36 \mu \mathrm{m})$ and $1.08 \mathrm{eV}(1.15 \mu \mathrm{m})$, see Figs. 4,6 and 7 in commented paper [1], respectively. Obviously, at room temperature this lowermost energy level is completely depopulated. As a consequence, any of the proposed diagrams can not explain the appearance of absorption in the spectral range of $1.4-1.7 \mu \mathrm{m}$, luminescence upon direct excitation around of $1.4 \mu \mathrm{m}$, and the corresponding laser generation [2].

To illustrate what we said above, we show in Fig. 1(a) experimental spectra of attenuation and photoluminescence (PL) measured in the photonic crystal fibre (PCF). The core of this fibre is constituted of a Bidoped silica without other co-dopant [3]. The corresponding energy level diagram that can be derived from these experiments is straightforward and we show it schematically in Fig. 1(b). Two absorption bands, at 820 and $1400 \mathrm{~nm}$ uniquely determine the position of corresponding energy levels. The direct excitation at $1400 \mathrm{~nm}$ results in the NIR PL. None of the diagrams of commented article reproduces this simple picture.

\section{Luminescence in the spectral region $1.15 \mu \mathrm{m}$}

The luminescence in the spectral region $1.15 \mu \mathrm{m}$ was first reported by Murata et al. [4] in aluminosilicate glass, not in the Bi-doped pure silica. After many years of research it was recognized that this luminescence is due to the presence of aluminium (or gallium in the case of $\mathrm{Ga} / \mathrm{Bi}$ co-doping) in the silica glass. Moreover, the $1.4 \mu \mathrm{m}$ luminescence is absent if the manufacturing technology ensures the arrangement of bismuth and aluminium ions in the close proximity, as can be seen in Fig. 2(a) where we show the luminescence of the properly designed $\mathrm{Al} /$ Bi co-doped silica glass (see the details in Refs. $[5,6,2]$ ). Thus, it was unequivocally established that 1.4 and $1.15 \mu \mathrm{m}$ luminescence bands belong to different centres, though both can coexist in the aluminosilicate glass. Obviously, Fig. 7 of the commented paper is in contradiction with experiment. Furthermore, the luminescence band at $1.15 \mu \mathrm{m}$ in aluminosilicate glass is always accompanied by the luminescence/absorption band around $1.65 \mathrm{eV}(750 \mathrm{~nm})$. However, the corresponding experimentally proven energy level is absent in Fig. 7 of the commented paper.

The Authors of the commented paper make reference to the paper [7], where the week luminescence band at $1068 \mathrm{~nm}$ was observed at low temperature (Fig. 3 in Ref. [7]). In Fig. 2(b) we show the normalised PL of bulk Bi-doped silica glasses without other co-dopant. Two samples are compared. The first one, \#1, was fabricated from the

\footnotetext{
* Corresponding author.
} 

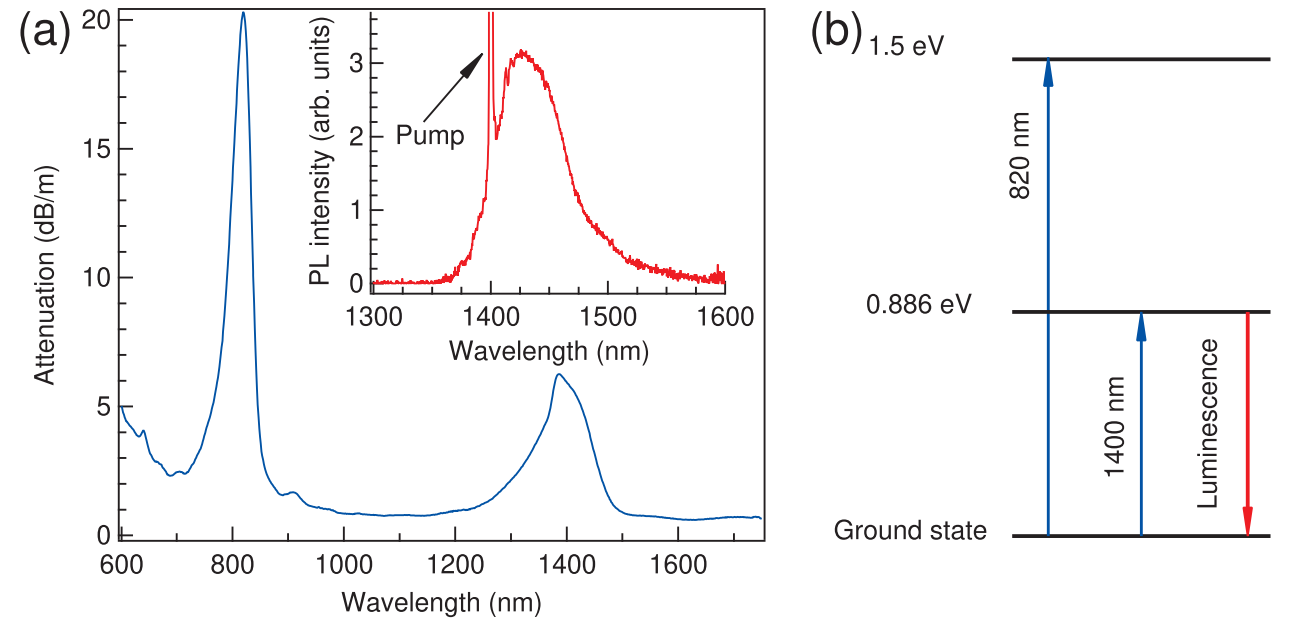

Fig. 1. (a) Attenuation spectrum of the Bismuth-doped silica core PCF. Inset: photoluminescence of the PCF upon excitation at $1400 \mathrm{~nm}$. (b) Energy level diagram.

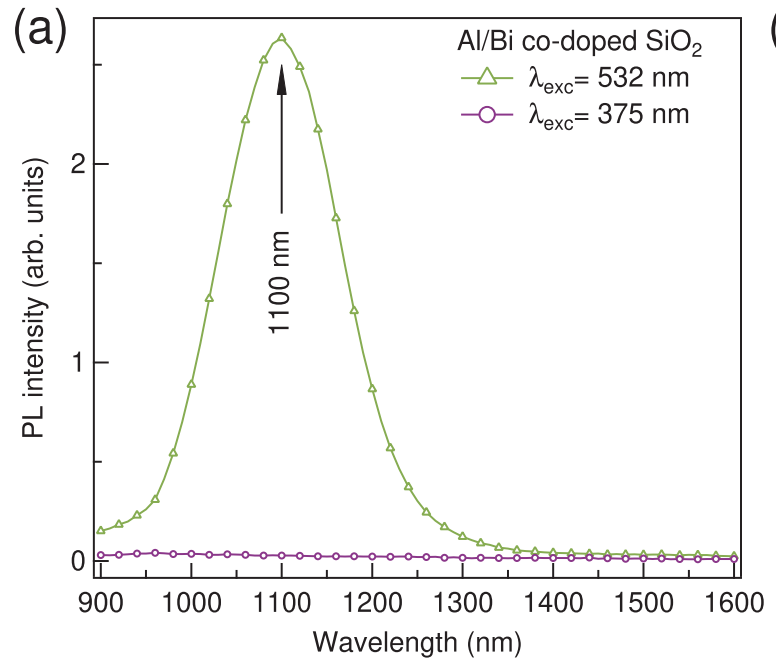

Fig. 2. (a) Photoluminescence of a bulk $\mathrm{Al} / \mathrm{Bi}$ co-doped silica glass.

nanoporous Bi-doped silica xerogel with the average pore size $\approx 24 \mathrm{~nm}$ and features a high Bismuth concentration $\geq 400 \mathrm{ppm}$. The second one, fabricated from the silica xerogel with the average pore size $\approx 10 \mathrm{~nm}$, features a low Bismuth concentration $\leq 100 \mathrm{ppm}$. The reduction in the pore size leads not only to a decrease in the final concentration of Bismuth, but also reduces clustering. It is seen in Fig. 2(b), that at low temperature upon excitation at $532 \mathrm{~nm}$ in the sample \#2 the PL bands around 1100 and $1400 \mathrm{~nm}$ are absent, while the intensity of red luminescence $(675 \mathrm{~nm})$ is significantly reduced. The nature of the red luminescence is out of the scope of the present Comment and will be addressed elsewhere. Regarding the appearance of the PL band around $1.1 \mu \mathrm{m}$, there are two possible explanations. If we assume that this band is associated with a univalent Bismuth, then it can be assigned to the forbidden transition $1 \Sigma^{-}\left(A_{2}\right) \longrightarrow 1 \Sigma^{+}\left(A_{1}\right)$ as it was calculated in the frame of crystal filed approach in our recent work [8]. Note, however, that none of the samples exhibits luminescence at $1.1 \mu \mathrm{m}$ upon excitation at $375 \mathrm{~nm}$ (in Fig. 2(b) we show it for \#1 sample only). Thus, alternatively, this band can be associated with clusters of Bismuth ions.

\section{Non-defective silica glass}

In a short paragraph, devoted to the non-defective $\mathrm{SiO}_{2}$ cluster, the Authors claim that the results of their calculations are in excellent agreement with the experimental data obtained by Mozzi and Warren [9]. In fact, however, even a brief comparison reveals qualitative

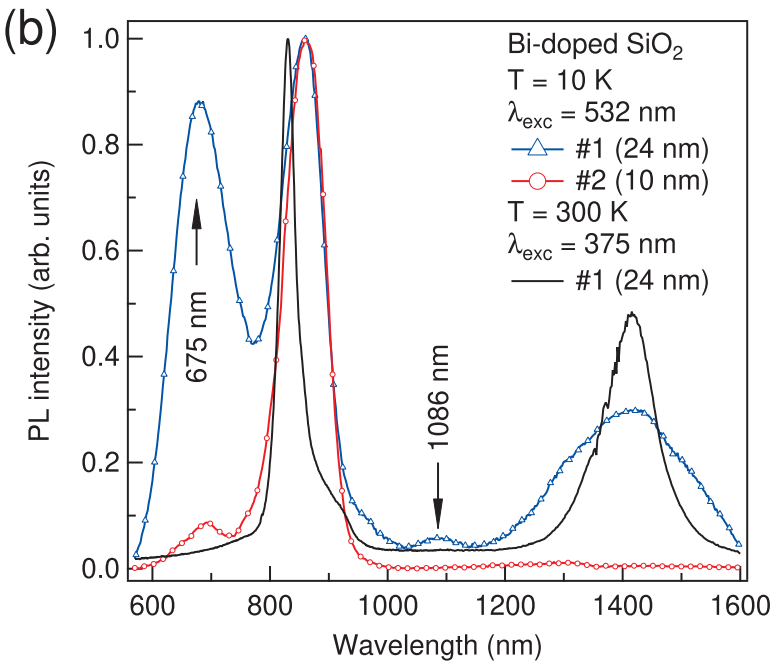

(b) Photoluminescence of Bi-doped silica glass without other dopant.

contradictions. For example, distributions of $\mathrm{Si}-\mathrm{O}$ bond lengths and $\mathrm{Si}-\mathrm{O}-\mathrm{Si}$ bond angles, shown in Fig. 2(a,b) of the commented paper, exhibit two well-distinguished maxima, while Mozzi et al. observed only one peak in each distribution, see Figs. 4 and 5 in Ref. [9]. On the other hand, calculations of silica glass structure had already been performed by Van Ginhoven et al. [10] using the same Vienna ab initio simulation package, and the agreement with experimental results was much better. This inconsistency raises doubts about the overall reliability of the calculations reported in the commented paper.

\section{Acknowledgements}

This work has been partially supported by the Ministry of Higher Education and Research, Hauts de France council and European Regional Development Fund (ERDF) through the CPER Photonics for Society P4S.

\section{References}

[1] B. Jia, P. Lu, Z. Peng, B. Yan, B. Yang, Y. Wang, G.-D. Peng, J. Lumin. 198 (2018) 384-388.

[2] I. Bufetov, M. Melkumov, S. Firstov, K. Riumkin, A. Shubin, V. Khopin, A. Guryanov, E. Dianov, IEEE J. Sel. Top. Quantum 20 (2014) 0903815.

[3] I. Razdobreev, H.E. Hamzaoui, L. Bigot, V. Arion, G. Bouwmans, A.L. Rouge, M. Bouazaoui, Opt. Express 18 (2010) 19479-19484.

[4] K. Murata, Y. Fujimoto, T. Kanabe, H. Fujita, M. Nakatsuka, Fusion Eng. Des. 44 (1999) 437-439. 
[5] I. Razdobreev, H.E. Hamzaoui, G. Bouwmans, M. Bouazaoui, V.B. Arion, Opt. Mater. Express 2 (2012) 205-213.

[6] I. Razdobreev, H.E. Hamzaoui, V.B. Arion, M. Bouazaoui, Opt. Express 22 (2014) 5659-5674.

[7] I. Razdobreev, H.E. Hamzaoui, V.Y. Ivanov, E.F. Kustov, B. Capoen, M. Bouazaoui,
Opt. Lett. 35 (2010) 1341-1343.

[8] O.V. Laguta, I.M. Razdobreev, Opt. Mater. 84 (2018) 103-108.

[9] R.L. Mozzi, B.E. Warren, J. Appl. Crystallogr. 2 (1969) 164-172.

[10] R.M. Van Ginhoven, H. Jónsson, L.R. Corrales, Phys. Rev. B 71 (2005) 024208. 